\title{
Original
}

\section{The Role of a Brain-specific Splice Variant of Ryanodine Receptor Type 1}

\author{
Takahiro HAYASHI ${ }^{1)}$, Hideto OYAMAdA ${ }^{1)}$, Toshiko YamazawA ${ }^{2)}$, \\ Takashi Murayama $^{3)}$, Tomoyuki MatsuokA ${ }^{1)}$, Keiichiro OhBA ${ }^{1)}$, \\ Masahide $\mathrm{NAKANO}^{1)}$ and Katsuji OGUCHI ${ }^{1)}$
}

\begin{abstract}
The ryanodine receptor type 1 (RyR1) is capable of homotetrameric assembly to form a $\mathrm{Ca}^{2+}$ release channel at intracellular $\mathrm{Ca}^{2+}$ storage sites such as endoplasmic reticulum (ER). The mRNA transcript encoding fulllength RyR1 is approximately $16 \mathrm{~kb}$ and is mainly distributed in excitable cells. A 2.4-kb mRNA splice variant from the 3'-terminal region of the $R y R 1$ gene coexists specifically in brain together with the full-length form, although the functions of this brain-specific splice variant remain unclear. To investigate the short form of RyR1 in intracellular $\mathrm{Ca}^{2+}$ signaling in brain at the cellular level, we established an experimental system whereby the green fluorescent protein (GFP)-tagged brain-specific variant of RyR1 is coexpressed with the full-length protein in the same cell. Both forms of RyR1 were localized in the ER. Caffeine-induced $\mathrm{Ca}^{2+}$-release activities in cells expressing both the brain-specific and full-length RyR1 were reduced compared to cells expressing only the full-length form of RyR1. These results suggested that coexpression of the brain-specific splice variant of RyR1 with its full-length counterpart modulates intracellular $\mathrm{Ca}^{2+}$ signaling by acting as a dominant-negative subunit of the $\mathrm{Ca}^{2+}$ release channel in a tissue-specific fashion.
\end{abstract}

Key words : ryanodine receptor, brain-specific splice variant, dominant-negative subunit, $\mathrm{Ca}^{2+}$ release channel, intracellular $\mathrm{Ca}^{2+}$ signaling

\section{Introduction}

The ryanodine receptor (RyR) is a family of $\mathrm{Ca}^{2+}$ release channels located in the membrane of intracellular $\mathrm{Ca}^{2+}$ storage organelles. Three mammalian RyR isoforms encoded by distinct genes have been cloned and fully sequenced; all are approximately 5000 amino acids long with a molecular weight of more than $550 \mathrm{kDa}$. Each monomeric RyR isoform can homotetramerize to form its respective functional $\mathrm{Ca}^{2+}$ release channel ${ }^{1)}$.

The type 1 RyR isoform (RyR1) is known as the skeletal-type RyR based on the initial purification and cDNA cloning from skeletal muscle ${ }^{2)}$. RyR1 is also expressed in the brain,

1) Department of Pharmacology, Showa University School of Medicine, 1-5-8 Hatanodai, Shinagawa-ku, Tokyo 1428555, Japan.

2) Department of Cellular and Molecular Pharmacology, Graduate School of Medicine, University of Tokyo.

3) Department of Pharmacology, Juntendo University School of Medicine. 
although in much smaller amounts than found in striated muscle ${ }^{3,4)}$. Takashima et $a l^{5)}$ reported the first evidence for a brain-specific transcript of RyR1, as an RNA transcript of approximately 2400 nucleotides that encoded only 656 amino acids. This represents a truncated version of RyR1 that would begin just before ${ }^{4382}$ methionine and extend to ${ }^{5037}$ serine of the full-length RyR1 protein. This protein is sorted into the membrane of endoplasmic reticulum (ER)-located intracellular $\mathrm{Ca}^{2+}$ storage sites in Chinese hamster ovary (CHO) cells transfected to express only this 3'-terminal portion of RyR1 cDNA. However, pharmacological experiments with these transformed $\mathrm{CHO}$ cells showed no $\mathrm{Ca}^{2+}$ release in response to caffeine, a representative RyR1-stimulating drug that induces a significant rise in intracellular $\mathrm{Ca}^{2+}$ concentration in $\mathrm{CHO}$ cells expressing full-length RyR1 ${ }^{5,6)}$. Substantial questions remain regarding the functional significance of brain cells expressing both the short and fulllength forms of RyR1.

This study therefore investigated possible roles of the brain-specific transcript of RyR1 in regulating intracellular $\mathrm{Ca}^{2+}$ signals with and without coexpressed full-length RyR1. We have established an experimental system for coexpressing both forms of RyR1 in brain that involves gene transfer of the brain-specific short form of RyR1cDNA to stable cell lines induced to express the full-length RyR1 protein.

\section{Materials and Methods}

The transfection efficiency in cells depends on the size of the target DNA, and the fulllength RyR1 cDNA (about 16,000 bp) was too long to be coexpressed quantitatively with the shorter cDNA of the brain-specific RyR1 transcript $(\sim 2,400 \mathrm{bp})$ transfected into the same cells. We therefore established the following methods to coexpress the two RyR1 cDNAs.

\section{Establishment of stable cell line induced to express full-length RyR1}

The Flp-In ${ }^{\mathrm{TM}} \mathrm{T}-\mathrm{REx}^{\mathrm{TM}}$ System (Invitrogen, Carlsbad, CA) used here ${ }^{7)}$ was modified to establish stable cell lines expressing full-length RyR1. In brief, the Flp-In T-REx293 cells (Invitrogen) were cultured in Dulbecco's modified Eagle's medium (Wako Pure Chemicals Industries, Osaka, Japan) containing 10\% fetal bovine serum and $100 \mathrm{U} / \mathrm{ml}$ of penicillin, and $100 \mu \mathrm{g} / \mathrm{ml}$ of streptomycin (Wako Pure Chemicals Industries). The tetracycline-inducible expression vector pcDNA5/FRT/TO (Invitrogen) was modified by the addition of an NheI site in its multicloning sites to insert full-length RyR1 cDNA $^{8)}$ digested by XbaI/EcoRV between the NheI and the EcoRV sites. Cotransfection of the expression vector containing full-length RyR1cDNA and the pOG44 vector encoding Flp recombinase (Invitrogen) was carried out by the calcium phosphate precipitation method using a Profection Mammalian Transfection System Kit (Promega, Madison, WI). Transfected cells were washed at $4 \mathrm{~h}$ after the transfection and allowed to grow in fresh medium for a further 2 days. The medium was replaced with the same growth medium containing $200 \mu \mathrm{g} / \mathrm{ml}$ hygromycin B (Wako 
Pure Chemicals Industries) to select transformed cells. This selection medium was changed every 3-4 days until the desired cell number was reached. Doxycycline, a stable tetracycline derivative, (Dox; $1 \mu \mathrm{g} / \mathrm{ml}$, Sigma -Aldrich Co, St. Louis, MO) was added to the selected cells for 48-72 $\mathrm{h}$ to induce the expression of full-length RyR1 protein. Immunocytochemical staining with polyclonal antibodies against the D2 region (amino acid 1358-1413) of rabbit RyR1 was carried out as previously described ${ }^{9)}$ to confirm the expression of exogenous RyR1 in the cells.

Coexpression of the brain-specific splice variant of RyR1 in the full-length RyR1-expressing cells

The domain corresponding to the brain-specific transcript of RyR $1^{5)}$, which is approximately $2.4 \mathrm{~kb}$ of the 3'-terminal of the full-length RyR1 cDNA (about $15 \mathrm{~kb}$ ), was amplified by using the high fidelity KOD Plus polymerase (TOYOBO, Osaka, Japan). PCR to make products tagged at the C-terminus with enhanced green fluorescent protein (GFP) was performed on the full-length RyR1cDNA template fused with the amino-terminal of GFP in pBluescript $\mathrm{KS}(+)$ as previously reported ${ }^{10)}$, with the following primer pairs (restriction enzyme recognition sites are underlined), XhoI-4382Met-F (5'-CCGCTCGAGGGATGCCCGATCCCACCAGCGACGAGG-3') and T3 (5'-AATTAACCCTCACTAAAGGG-3'). Another set of primers for making the PCR product fused with the C-terminal of GFP was as follows: the RyR1C (+KOZAC)-F (5'-GCGGCTAGCGCCGCCACCATGGCCGATCCCACCAGCGACGAGGTGCACGG-3')/RyR1C (EcoRV)-R (5'-CAAGCTTGATATCGAATTCCTGCAGCCCGGGGG-3') ; restriction enzyme recognition sites are underlined and the Kozac initiation sequence ${ }^{11)}$ for translation is shown in italics). The PCR products were ligated into the GFP expression vectors ${ }^{12)}$ after double digestion of the PCR products with restriction enzymes Xhol/HindIII for the former PCR product or NheI/EcoRV for the latter product. DNA sequencing was performed by Macrogen Japan (Tokyo, Japan) to validate the nucleotide sequence encoding the brain-specific RyR1 transcript. These GFP-tagged expression vectors were transfected into the Flp-In T-REx293 cells (Invitrogen) by the same procedure as described.

To coexpress the GFP-tagged brain-specific form of RyR1 with the full-length RyR1 in the same cells, each GFP expression vector was introduced into the previously established HEK293 cells Dox-induced to express full-length RyR1 according to the calcium phosphate precipitation methods of the same kit (Promega).

\section{SDS-polyacrylamide gel electrophoresis (PAGE) and western blotting}

SDS-PAGE was performed on $2-12 \%$ linear gradient gels with standard proteins at (in kDa) 205 (myosin heavy chain), 116 (b-galactosidase), 97.4 (phosphorylase b), 66 (bovine serum albumin), and 45 (ovalbumin). Gels were stained with Coomassie Brilliant Blue and the separated proteins were electrophoretically transferred overnight onto PVDF membranes in the presence $0.02 \%$ SDS. Immunodetection was carried out with an ECL system (GE 
Healthcare UK, Ltd., Little Chalfont, Buckinghamshire, England) using primary antibodies against the D2 region of RyR1 and peroxidase-conjugated secondary antibodies.

\section{Imaging of intracellular $\mathrm{Ca}^{2+}$ concentration}

Changes in intracellular $\mathrm{Ca}^{2+}$ levels of cultured cells were measured using the $\mathrm{Ca}^{2+}$ indicator dye Fura-2. Cells were loaded with $4 \mu \mathrm{M}$ Fura-2/AM (Molecular Probes, Eugene, $\mathrm{OR}$ ) in a physiological salt solution $(150 \mathrm{mM} \mathrm{NaCl}, 4 \mathrm{mM} \mathrm{KCl}, 2 \mathrm{mM} \mathrm{CaCl}, 1 \mathrm{mM} \mathrm{MgCl}$, $5.6 \mathrm{mM}$ glucose, $5 \mathrm{mM}$ HEPES, adjusted to $\mathrm{pH} 7.4$ with $\mathrm{NaOH}$ ) containing $0.1 \%$ bovine serum albumin V (Sigma-Aldrich) for 30 minutes at room temperature. Cells were viewed under an inverted fluorescence microscope (IX70, Olympus, Tokyo, Japan) equipped with a charge-coupled device camera (Rolera, QImaging, Burnaby, Canada). Changes in the intracellular $\mathrm{Ca}^{2+}$ concentration were measured by monitoring the ratio of the fluorescence signals at $515-550 \mathrm{~nm}$ with alternate excitations at 345 and $380 \mathrm{~nm}$. Image analysis was performed using IPLab software (Signal Analytics, Glen Allen, VA). Images were converted to 345/380 ratio images by ImageJ software (National Institutes of Health, Bethesda, MD) and then averaged over the whole area sampled. Images were captured by a high-sensitivity chargecoupled device digital camera (DP70, Olympus) using image-capture software (DP Control, Olympus), and analyzed using ImageJ. Changes in the ratios of the fluorescence intensity at $345 \mathrm{~nm}$ to that at $380 \mathrm{~nm}$ were normalized to the average resting value before the first drug application.

\section{Reagents}

Caffeine was purchased from Wako Pure Chemicals Industries.

\section{Data analysis}

All results from the normalized values of the fluorescence ratios are expressed as mean \pm SEM. Statistical differences between groups were evaluated by unpaired t-tests. A $P$ value of 0.0005 or less was considered to indicate a significant difference between groups.

\section{Results}

Prior to applying the Flp-In T-REx system, we performed a trial with a simple method to express two different genes transiently using a single expression vector such as the pIRES (internal ribosome entry site) bicistronic expression vector (Clontech Laboratories, Mountain View, CA) or pBI (bidirectional) expression vector (Clontech) ${ }^{13)}$. However, the final size of these expression vectors $(>250,000 \mathrm{bp}$ ) was too large for the efficient expression of both recombinant proteins. Therefore, we instead established stable cell lines expressing full-length RyR1 encoded by the larger vectors, and then transiently expressed the brain-specific form of RyR1 in the stably expressing cells by standard transfection procedures. 
Establishment of stable HEK293 cell lines induced to express full-length RyR1

Using the Flp-In T-REx system, we established a stable cell line of HEK293 cells Doxinducibly expressing the full-length RyR1. This system allowed integration of the fulllength cDNA of RyR1 in mammalian cells at a specific integrated FRT site in the genome. SDS-PAGE and Western blotting of cell lysates from multiple stable clones selected by hygromycin B resistance (Fig. 1A) revealed the expression of full-length RyR1 to approximately the same level in all six clones (Fig. 1B). Immunocytochemical analysis confirmed the similar efficiencies of RyR1 expression across the stable cell lines (Fig 1C), showing much stronger fluorescent signal in the cytoplasm than in the nucleus, as previously reported $^{12-14)}$. These results indicated highly reproducible expression of exogenous RyR1 at the expected location from cell to cell and from clone to clone using this experimental system.

\section{Expression of the brain-specific transcript of RyR1 in HEK293 cells}

We constructed the truncated form of RyR1cDNA corresponding to the brain-specific transcript of RyR1 to be expressed as a GFP-fusion protein. Stable cell lines inducibly expressing the brain-specific form of RyR1 were also established by the Flp-In T-Rex system. GFP-fluorescence was observed for both clones inducibly expressing the short forms tagged by GFP at its $\mathrm{N}$ - or C- terminus respectively, although the signal intensity was slightly stronger with the GFP at the C-terminal of RyR1 compared to tagging at the N-terminus (Fig. 2A and 2C). The intracellular distribution of the GFP-fusion proteins was predominantly cytoplasmic (Fig. 2A and 2C), as described previously with full-length RyR1GFP fusions ${ }^{12,14)}$. These results suggested that both of the GFP-tagged brain-specific RyR1s were expressed appropriately at intracellular $\mathrm{Ca}^{2+}$ store sites such as endoplasmic reticulum where intracellular $\mathrm{Ca}^{2+}$ release channels are located to transduce intracellular $\mathrm{Ca}^{2+}$ signaling ${ }^{15)}$.

Coexpression of the brain-specific transcript of RyR1 with full-length RyR1 in HEK293 cells

We introduced the expression vectors encoding the brain-specific short form of RyR1cDNA into the cells expressing full-length RyR1 in the presence of Dox by the calcium phosphate precipitation method. Some cells in the culture dishes emitted GFPfluorescence (GFP-positive) indicating expression of the brain-specific form of RyR1, while other cells expressing full-length RyR1 alone showed no GFP-fluorescence (GFPnegative). Approximately 48 hours after the gene-transfer, we compared the functional properties of the $\mathrm{Ca}^{2+}$ release channels of the GFP-positive cells with those of the GFPnegative cells in the same dishes by applications of caffeine as an agonist of the $\mathrm{Ca}^{2+}$ release function of RyR1. All cells showed dose-dependent increases in intracellular $\mathrm{Ca}^{2+}$ concentration measured fluorimetrically (345/380 ratio) obtained using $345 \mathrm{~nm}$ and $380 \mathrm{~nm}$ of excitation light under a fluorescence microscope. However, the caffeine-induced increases in 
A

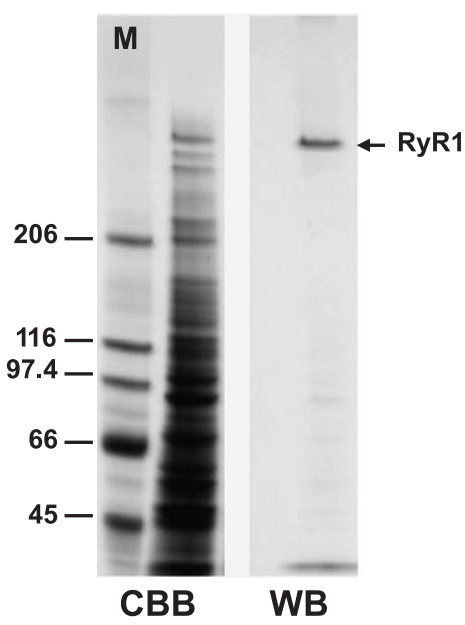

B

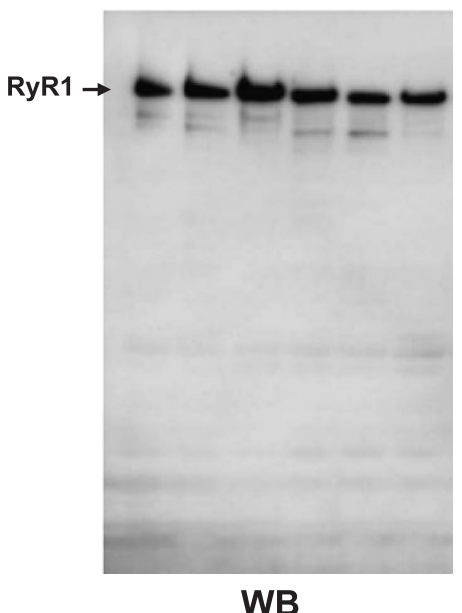

WB

C
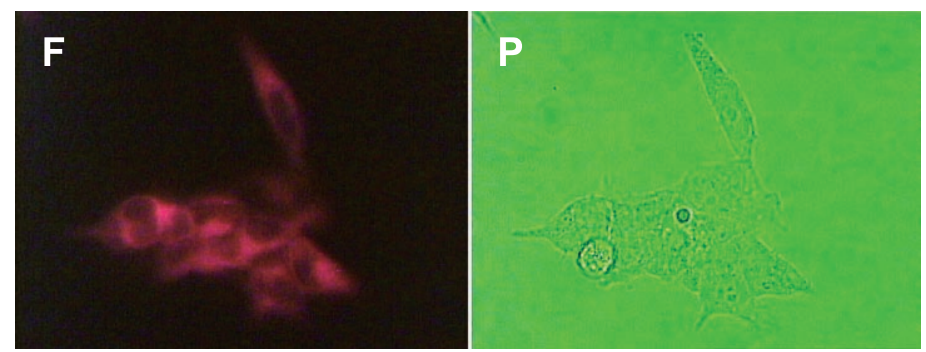

Fig. 1. Establishment of stable HEK293 cell lines induced to express full-length RyR1

(A) SDS-PAGE and Western blotting of whole cell extracts from the hygromycin B-selected HEK293 cells as the stable cell line induced to express full-length RyR1. Size markers (M) and $30 \mu \mathrm{g}$ of the whole cell extract were subjected SDS-PAGE on a gradient gel and stained with Coomassie Brilliant Blue (CBB) (left). Similar gels were transferred onto PVDF membrane and probed with anti-D2 of RyR1 polyclonal antibodies (right). (B) Quantitative comparison of expressed RyR1 from six independent stable cell lines. Western blotting was performed in each cell extract from six clones of the stable cell lines induced to express RyR1 with the anti-D2 of RyR1 antibodies. (C) Expression and distribution of exogenous RyR1 in HEK293 cells. Immunocytochemical staining of the expressed RyR1 in individual cells was performed with anti-D2 of RyR1 polyclonal antibodies and TRITC-conjugated secondary antibodies. The TRITC-red fluorescent images from the Dox-induced HEK293 cells expressing RyR1 are shown in the left panel (F) and the phase contrast images of the same field are shown in the right panel (P).

intracellular $\mathrm{Ca}^{2+}$ concentration were significantly decreased in GFP-positive cells compared to GFP-negative cells, while the same $\mathrm{Ca}^{2+}$ concentrations were observed in both types of cells under resting conditions without caffeine (Fig. 3A and 3B). The inhibitory effects observed in GFP-positive cells were decreased in a dose-dependent manner to the higher 

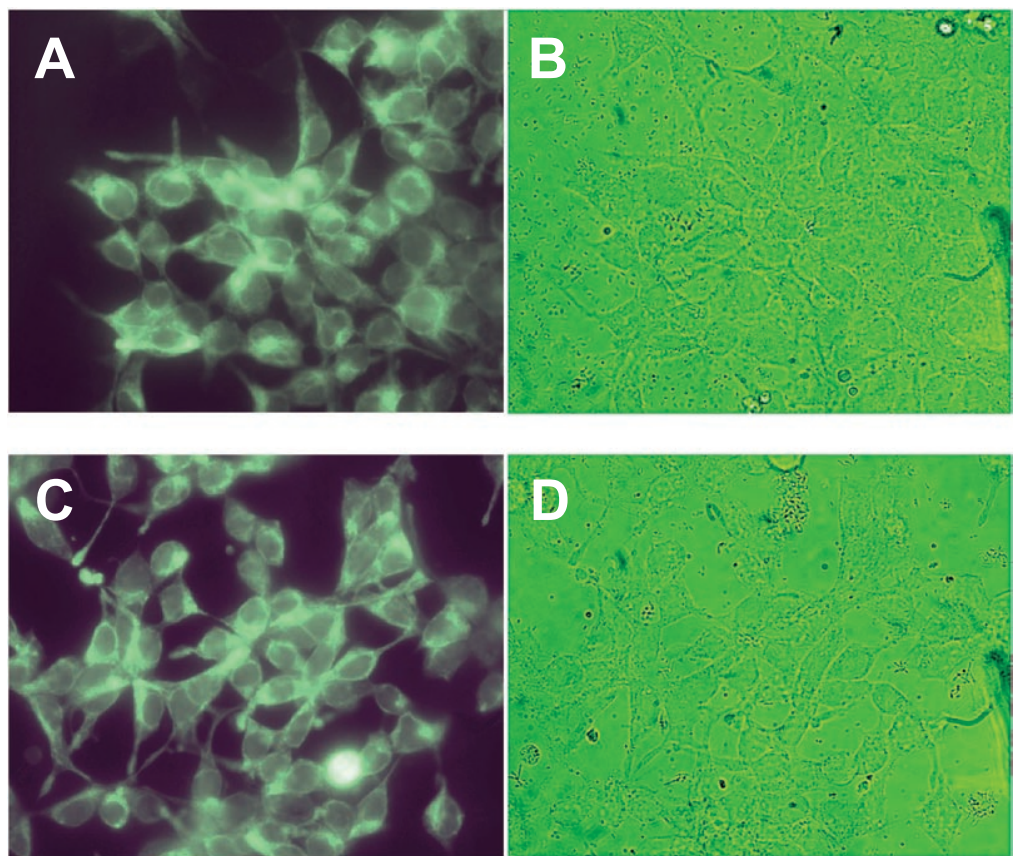

Fig. 2. Expression and distribution of the exogenous brain-specific form of RyR1 in HEK293 cells

Fluorescence images of HEK293 cells expressing the GFP-tagged brain-specific form of RyR1 fused at the N-terminus of RyR1 (A) or at the C-terminus (C). The corresponding phase-contrast images of the same fields of (A) and (C) are shown in (B) and (D), respectively.

concentration of caffeine. Moreover, the suppressive activities of the brain-specific form of RyR1 were stronger in cells expressing the GFP tagged at the N-terminal of RyR1 than in cells expressing the C-terminal tagged protein (Fig. 4A and 4B).

\section{Discussion}

In this study, we developed an experimental system for coexpressing two genes that differ by approximately 10 -fold in length in the same cells. We showed the novel finding that coexpression of the brain-specific transcript of RyR1 and full-length RyR1 in the same cell altered the sensitivity of $\mathrm{Ca}^{2+}$ release channels in that cell.

Molecular cloning and hydropathy plot analysis of predicted amino acid sequences (about 5000 amino acids as the full length) indicated that a large hydrophilic N-terminal 'foot' region and smaller hydrophobic C-terminal (10-20\% of the protein; last 500-1000 amino acids) region containing putative 4 to 10 transmembrane segments form the conduction pore of a $\mathrm{Ca}^{2+}$ release channel ${ }^{2,16)}$. Heterologous expression of the truncated RyR1 demonstrated that the C-terminal 1030 amino acids could function as an ion channel in planar lipid bilayers ${ }^{17,18)}$. Recently, gel filtration analysis of purified C-terminal regions of 

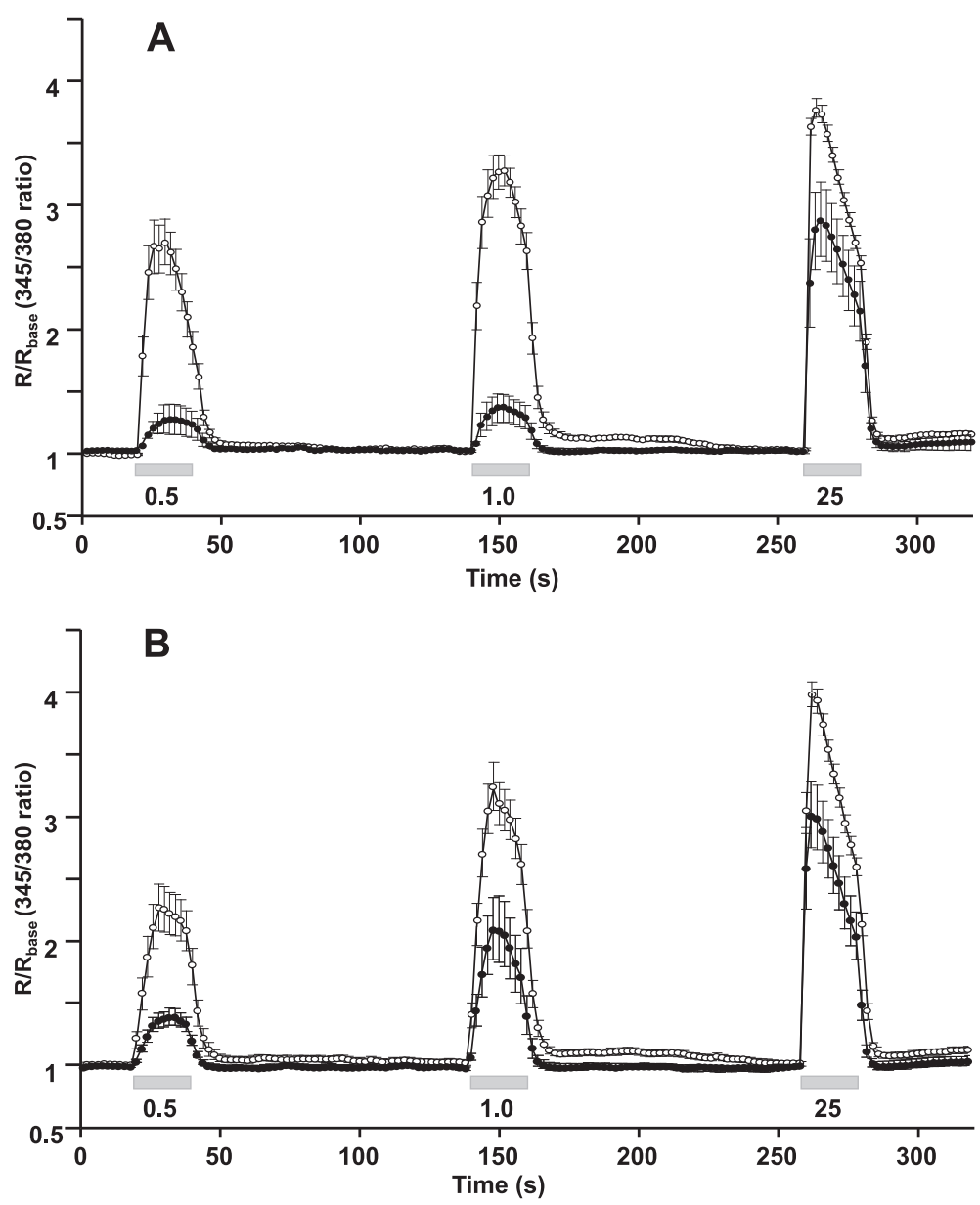

Fig. 3. Effects of Coexpression of the brain-specific form of RyR1 on caffeine-induced intracellular $\mathrm{Ca}^{2+}$ mobilization in HEK293 cells expressing full-length RyR1

Time courses of intracellular $\mathrm{Ca}^{2+}$ concentration changes in the transfected HEK293 cells coexpressing full-length RyR1 and the brain-specific form tagged by GFP at the N-terminus (A) or at the C-terminus (B). The closed- and open- symbols are from the GFP-positive or GFP-negative cells, respectively. Applications of caffeine are shown in the gray bars at the concentrations indicated $(\mathrm{mM})$. The vertical scale shows the fluorescence ratio of fura2 intensities (as described in Materials and Methods) and the horizontal scale shows the timeline $(\mathrm{sec})$. Values are expressed as the mean $\pm \mathrm{SEM}$.

the RyR1 protein showed that the last $209^{19)}$ or 100 amino acids ${ }^{20)}$ were capable of selftetramerization as structurally required for the functional ion channel. Therefore, it is possible that the brain-specific transcript of RyR1 (last 656 amino acids) is incorporated into the assembly of RyR1 $\mathrm{Ca}^{2+}$ release channels as a dominant-negative regulator.

GFP-tagging at either end of the brain-specific RyR1 produced slightly different inhibitory effects on the caffeine-induced $\mathrm{Ca}^{2+}$ release in cells coexpressing full-length RyR1. Protein- 
A

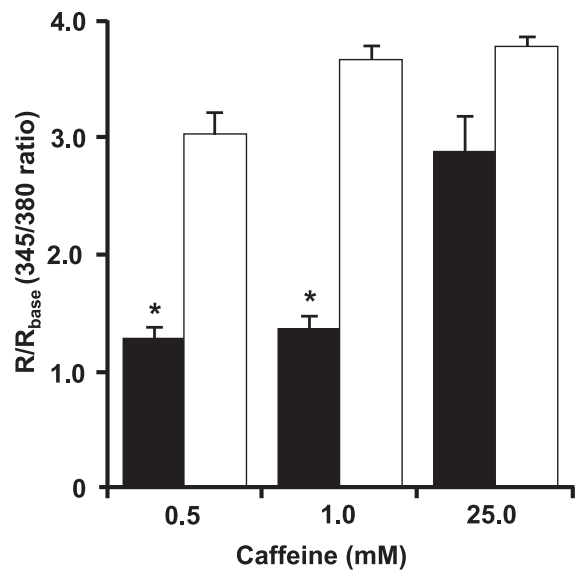

B

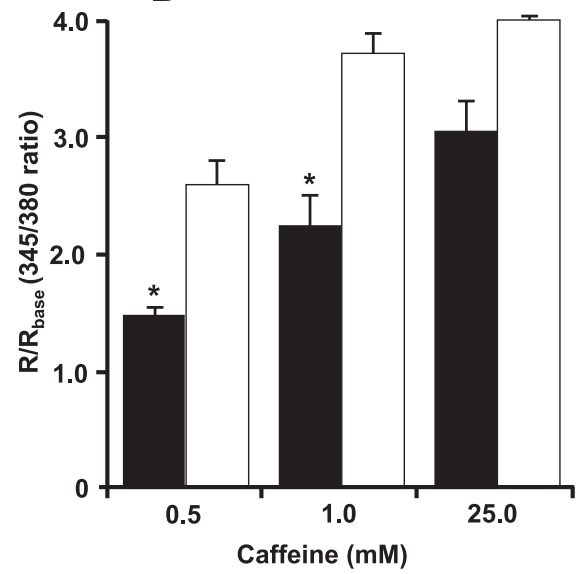

Fig. 4. Inhibitory effect of Coexpression of the brain-specific form of RyR1 with full-length RyR1 on caffeine-induced $\mathrm{Ca}^{2+}$-releasing activities in HEK293 cells

Each column shows the peak level (mean \pm SEM, $\mathrm{n}=7-46$ ) of intracellular $\mathrm{Ca}^{2+}$ response induced by caffeine at the concentration indicated $(\mathrm{mM}) .{ }^{*} P<0.0005$ versus HEK293 cells expressing the full-length of RyR1 alone (white columns) that did not show any GFP fluorescence in the cytosol.

protein interaction analyses have shown that removing the final 15 amino acids from the C-terminus of RyR1 eliminates the capacity for oligomeric association ${ }^{21)}$. Moreover, GFP fusion to the $\mathrm{C}$-terminal end of the full-length protein completely abrogates the caffeineinduced $\mathrm{Ca}^{2+}$ release activity ${ }^{10,22)}$. These results indicated that slight conformational changes to RyR1 could influence the incorporation of the dominant-negative subunit (truncated RyR1) into the tetramer.

Malignant hyperthermia $(\mathrm{MH})$ is an autosomal dominant pharmacogenetic disorder of skeletal muscle, triggered in predisposed individuals by inhalation of anesthetics (e.g. halothane) or by depolarizing muscle relaxants (e.g. succinylcholine) ${ }^{23)}$. More than 80 different mutations in the RyR1 gene have been found in patients with $\mathrm{MH}$ and/or its related congenical myopathy of central core disease (CCD), which is characterized by large amorphous areas (cores) that lack mitochondria or oxidative enzyme activity and hypotonia during infancy, proximal muscle weakness, delayed motor development, and reduced muscle bulk. Although the reported RyR1 mutations cluster in three separate regions [the $\mathrm{N}$-terminus, the central domain, and the $\mathrm{C}$-terminus containing the channel pore ${ }^{23,24)}$ ], MH-linked mutations are mostly found in the N-terminal and central regions. The MH-related amino acid substitutions in RyR1 exogenously expressed in cultured cells enhances the caffeine or halothane sensitivities of the $\mathrm{Ca}^{2+}$ release channel activities, which has also been reported in muscle biopsies from $\mathrm{MH}$ patients ${ }^{8,13)}$. The brain-specific short form of RyR1 might therefore confer local protective effects on the MH symptoms by blocking the function of the MH-related regions of full-length RyR1. 
RyR genes contain more than 100 exons, and many tissue-specific or developmentally regulated splice variants have been reported ${ }^{25-27)}$. One such variant that is overexpressed in adult myotonic dystrophy type 1 was recently implicated to be of pathophysiological significance ${ }^{28)}$, although the physiological roles of RyR1 variants largely remain unknown. Further studies into the roles of RyR1 splice variants should provide important insight into not only universal intracellular $\mathrm{Ca}^{2+}$ signaling but also the tissue-specific regulation of $\mathrm{Ca}^{2+}$ signaling in specific tissues including brain and muscle ${ }^{29)}$.

\section{References}

1) Zissimopoulos $S$ and Lai FA: Ryanodine receptor, function and pathophysiology. In: Calcium : a matter of life or death, Krebs J and Michalak M (Eds), Elsevier, Amsterdam, pp 287-342 (2007) (New comprehensive biochemistry ; V. 41)

2) Takeshima H, Nishimura S, Matsumoto T, Ishida H, Kanagawa K, Minamino N, Matsuo H, Ueda M, Hanaoka $\mathrm{M}$, Hirose $\mathrm{T}$ and Numa S: Primary structure and expression from complimentary DNA of skeletal muscle ryanodine receptor. Nature 399:439-445 (1989)

3) Kuwajima G, Futastugi A, Niinobe M, Nakanishi S and Mikoshiba K: Two types of ryanodine receptors in mouse brain: skeletal muscle type exclusively in Purkinje cells and cardiac muscle type in various neurons. Neuron 9 : 1133-1142 (1992)

4) Furuichi T, Furutama D, Hakamata $Y$, Nakai J, Takeshima H and Mikoshiba K: Multiple types of ryanodine receptor/Ca ${ }^{2+}$ release channels are differentially expressed in rabbit brain. J Neurosci 14:4794-4805 (1994)

5) Takeshima H, Nishimura S, Nishi $M$, Ikeda $M$ and Sugimoto $T$ : A brain-specific transcript from the 3'-terminal region of the skeletal muscle ryanodine receptor gene. FEBS Lett 322 : 105-110 (1993)

6) Penner $R$, Neher E, Takeshima $H$, Nishimura $S$ and Numa $S$ : Functinal expression of the calcium release channel from skeletal muscle ryanodine receptor cDNA. FEBS Lett 259 : 217-221 (1989)

7) Ubukata Y, Oyamada H, Yamazawa T, Murayama T, Tsuji M, Hayashi T and Oguchi K : Nateglinide stimulates $\mathrm{Ca}^{2+}$ release from endoplasmic reticulum via ryanodine receptor type 1. Showa Univ J Med Sci 20:199-208 (2008)

8) Tong J, Oyamada H, Demaurex N, Grinstein S, McCarthy TV and MacLennan DH : Caffeine and halothane sensitivity of intracellular $\mathrm{Ca}^{2+}$ release is altered by 15 calcium release channel (ryanodine receptor) mutations associated with malignant hyperthermia and/or central core disease. J Biol Chem 272 : 26332-26339 (1997)

9) Murayama T, Oba T, Katayama E, Oyamada H, Oguchi K, Kobayashi M, Otsuka K and Ogawa Y: Further characterization of the ryanodine receptor (RyR3) purified from rabbit diaphragm. J Biol Chem 274 : 1729717308 (1999)

10) Wakatsuki K, Oyamada H, Tsuji M, Hirose K, Yamazawa T, Iino M, Yamamoto T and Oguchi K: Visualization of ryanodine receptor fused with green fluorescent protein in living cells. Jpn J Pharmacol 76(suppl) : 236 (1998)

11) Kozac M: The scanning model for translation : an update. J Cell Biol 108 : 229-241 (1989)

12) Makino $T$, Oyamada $H$, Ubukata $Y$ and Oguchi $K$ : Distribution of retention signals to the endoplasmic reticulum in the type 1 ryanodine receptor $\left(\mathrm{Ca}^{2+}\right.$ release channel). Showa Univ J Med Sci 18:171-178 (2006)

13) Oyamada H, Oguchi K, Saitoh N, Yamazawa T, Hirose K, Kawana Y, Wakatsuki K, Oguchi K, Tagami M, Hanaoka K, Endo $\mathrm{M}$ and Iino $\mathrm{M}$ : Novel mutations in C-terminal channel region of the ryanodine receptor in malignant hyperthermia patients. Jpn J Pharmacol 88 : 159-166 (2002)

14) Kikuchi T, Oyamada H, Tsuji $\mathrm{M}$ and Oguchi $\mathrm{K}$ : Construction and expression of ryanodine receptor serial deletion clones in Chinese hamster ovary cells. Showa Univ J Med Sci 15:37-46 (2003)

15) Berridge MJ : Elementary and global aspects of calcium signalling. J Physiol 499: 291-306 (1997)

16) Zorzato F, Fuji J, Otsu K, Phillips M, Green NM, Lai FA, Meissner G and MacLennan DH : Molecular 
cloning of cDNA encoding human and rabbit forms of $\mathrm{Ca}^{2+}$ release channel (ryanodine receptor) of skeletal muscle sarcoplasmic reticulum. J Biol Chem $265:$ 2244-2256 (1990)

17) Bhat MB, Zhao J, Takeshima $\mathrm{H}$ and $\mathrm{Ma} \mathrm{J}$ : Functional calcium release channel formed by the carboxy-terminal portion of ryanodine receptor. Biophys $J$ 73 : 1329-1336 (1997)

18) Bhat MB, Zhao J, Zang W, Balke CW, Takeshima H, Wier WG and Ma J : Caffeine-induced release of intracellular $\mathrm{Ca}^{2+}$ from Chinese hamster ovary cells expressing skeletal muscle ryanodine receptor. Effect on fulllength and carboxyl-terminal portion of $\mathrm{Ca}^{2+}$ release channels. J Gen Physiol 110 : 749-762 (1997)

19) Kang GB, Song HE, Song DW, Kim MK, Rho SH, Kim DH and Eom SH : Overexpression and purification of the RyR1 pore-forming region. Protein Pep Lett $14: 742-746$ (2007)

20) Lee EH and Allen PD: Homo-dimerization of RyR1 C-terminus via charged residues in random coils or in an a-helix. Exp Mol Med 39: 594-602 (2007)

21) Gao L, Tripathy A, Lu X and Meissner G: Evidence of a role of C-terminal amino acid residues in skeletal muscle $\mathrm{Ca}^{2+}$ release channel (ryanodine receptor) function. FEBS Lett 412:223-226 (1997)

22) Treves S, Pouliquin P, Moccagatta and Zorzato F: Functional properties of EGFP-tagged skeletal muscle calcium-release channel (ryanodine receptor) expressed in COS-7 cells : sensitivity to caffeine and 4-chloro-mcresol. Cell Calcium $31: 1-12$ (2002)

23) Loke $\mathrm{J}$ and MacLennan DH : Malignant hyperthermia and central core disease. Am J Med 104:470-486 (1998)

24) Treves S, Anderson A, Ducreux S, Divet A, Bleunven C, Grasso C, Paesante S and Zorzato F: Ryanodine receptor 1 mutations, dysregulation of calcium homeostasis and neuromuscular disorders. Neuromuscul Disord 15 : 577-587 (2005)

25) Dabertrand F, Morel JL, Sorrentino V, Mironneau J, Mironneau C and Macrez N: Modulation of calcium signalling by dominant negative splice variant of ryanodine receptor subtype 3 in native smooth muscle cells. Cell Calcium $40: 11-21$ (2006)

26) Futatsugi A, Kuwajima $G$ and Mikoshiba $K$ : Tissue-specific and developmentally regulated alternative splicing in mouse skeletal muscle ryanodine recptor mRNA. Biochem J 305:373-378 (1995)

27) Mori F, Fukaya M, Abe H, Wakabayashi K and Watanabe M: Developmental changes in expression of three ryanodine receptor mRNA in the mouse brain. Neurosci Lett 285:57-60 (2000)

28) Kimura T, Nakamori M, Lueck JD, Pouliquin P, Aoike F, Fujimura H, Dirksen RT, Takahashi MP, Dulhunty AF and Sakoba S: Altered mRNA splicing of the skeletal muscle ryanodine receptor and sarcoplasmic/endoplasmic reticulum, $\mathrm{Ca}^{2+}$-ATPase in myotonic dystrophy type 1 . Hum Mol Genet 14 : 2189-2200 (2005)

29) Berridge MJ, Bootman MD and Roderick HL: Calcium signaling: dynamics, homeostasis and remodeling. Nat Rev Mol Cell Biol 4 : 517-529 (2003)

[Received February 10, 2010 : Accepted February 18, 2010] 